\title{
Diabetic Ketoacidosis with Extreme Hypernatremia in a 4-Year-Old Girl
}

\author{
Manish Kumar Arya, Sheikh Minhaj Ahmed, Krishnakumar N. Shah, Uma S. Ali \\ Department of Pediatrics, Lilavati Hospital and Research Centre, Mumbai, Maharashtra, India
}

\section{Abstract}

A 4-year-old girl admitted with altered mental status, new-onset diabetes mellitus, and diabetic ketoacidosis (DKA) had a rapid rise in serum sodium from $158 \mathrm{mEq} / \mathrm{L}$ (corrected sodium $165 \mathrm{mEq} / \mathrm{L}$ ) at the admission to $204 \mathrm{mEq} / \mathrm{L}$ within 18 hours of admission despite standard fluid and insulin therapy recommended for the treatment of DKA. During her illness, she developed arterial and deep vein thrombosis (DVT), bloodstream infection with Candida species, and extensive skin blistering and denudation. The child needed mechanical ventilation, insulin infusion, careful fluid titration to bring down the sodium gradually, and low-molecular weight heparin for her DVT. She had a prolonged Intensive Care Unit and hospital stay but recovered completely without any neurological sequelae.

Keywords: Deep vein thrombosis, diabetic ketoacidosis, extreme hypernatremia, skin blisters

\section{INTRODUCTION}

The most common sodium change observed in diabetic ketoacidosis (DKA) is hyponatremia with corrected sodium being in the eunatremic range ${ }^{[1,2]}$ Although mild hypernatremia can be seen in $30 \%$ of patients presenting with DKA, extremely severe hypernatremia in the range of $200 \mathrm{mEq} / \mathrm{L}$ in DKA has never been reported before. We present a case of severe DKA in a 4-year-old girl with a serum sodium of $204 \mathrm{mEq} / \mathrm{L}$ with intact neurological recovery.

\section{Case Report}

A 4-year 4-month-old girl was referred to our hospital for DKA with rapidly rising serum sodium with a history of fever, vomiting, and altered sensorium. The child also had symptoms of polyuria, nocturia and polydipsia for a few weeks prior to admission. Her blood glucose was $>500 \mathrm{mg} / \mathrm{dL}$, and arterial blood gas showed $\mathrm{pH} 7.03, \mathrm{pCO}_{2} 16.2 \mathrm{mmHg}$, $\mathrm{HCO}_{3} 4.3 \mathrm{mEq} / \mathrm{L}$, and a base deficit of -27 , with a serum sodium of $158 \mathrm{mEq} / \mathrm{L}$ (corrected serum $\mathrm{Na}$ of $165 \mathrm{mEq} / \mathrm{L}$ ). The management of DKA was initiated according to the standard protocol. However, serum sodium continued to rise and reached $189 \mathrm{mEq} / \mathrm{L}$.

On admission, the child was drowsy with severe dehydration, had acidotic breathing and was in hypotensive shock with

\begin{tabular}{|l|l|}
\hline \multicolumn{3}{|c|}{ Access this article online } \\
\hline Quick Response Code: & Website: \\
\hline & www.ijccm.org \\
& \\
\hline
\end{tabular}

blood pressure (BP) of 70/50 mm Hg. On the central nervous system examination, she had a Glasgow Coma scale (GCS) of $7 / 15$, hypertonia with brisk reflexes in all the four limbs.

She was given $10 \mathrm{ml} / \mathrm{kg}$ of normal saline fluid bolus and vasoactive drug infusions to support her BP. Her dehydration was estimated to be $9 \%$, and she was started on an appropriate volume of fluid given as $0.45 \mathrm{NS}$. Insulin infusion was continued. The free water correction calculated at $4 \mathrm{ml} / \mathrm{kg} /$ percent of dehydration was also started to correct her hypernatremia. In a view of her low GCS, she was mechanically ventilated. The right femoral central venous catheter and left radial arterial line were secured for hemodynamic monitoring. She was started on intravenous (IV) ceftriaxone.

Investigations revealed $\mathrm{Hb} 12.9 \mathrm{~g} \%$, white blood cell of $25,300 / \mathrm{mm}^{3}$ with polymorphs of $64 \%$, and platelets 529,000 per microliter. Blood urea nitrogen and serum creatinine were $28 \mathrm{mg} / \mathrm{dl}$ and $0.83 \mathrm{mg} / \mathrm{dl}$, respectively. Serum

Address for correspondence: Dr. Manish Kumar Arya, 201, Sai Niketan, Opp Saibaba Mandir, Saibaba Nagar, Borivali West, Mumbai - 400 092, Maharashtra, India. E-mail: wildbluewind@gmail.com

This is an open access article distributed under the terms of the Creative Commons Attribution-NonCommercial-ShareAlike 3.0 License, which allows others to remix, tweak, and build upon the work non-commercially, as long as the author is credited and the new creations are licensed under the identical terms.

For reprints contact: reprints@medknow.com

How to cite this article: Arya MK, Ahmed SM, Shah KN, Ali US. Diabetic ketoacidosis with extreme hypernatremia in a 4-year-old girl. Indian J Crit Care Med 2017;21:610-2. 
glutamate oxaloacetate transaminase was $10 \mathrm{U} / \mathrm{L}$, serum glutamate pyruvate transaminase was $10 \mathrm{U} / \mathrm{L}$, serum lactate was $1.02 \mathrm{mmol} / \mathrm{L}$ (Normal range $[\mathrm{N}]-0.9-1.6 \mathrm{mmol} / \mathrm{L}$ ), and serum ketones were $3.2 \mathrm{mmol} / \mathrm{L}(\mathrm{N}-0.05-0.29 \mathrm{mmol} / \mathrm{L})$. The urine ketones were $1+$. C-peptide level was $0.08 \mathrm{ng} / \mathrm{mL}(\mathrm{N}-0.08-$ $3.1 \mathrm{ng} / \mathrm{mL})$, and HbAlc was $16.2 \%(\mathrm{~N}-4 \%-6 \%)$. Despite the free water correction serum sodium rose to $204 \mathrm{mEq} / \mathrm{L}$ over the next $6 \mathrm{~h}$. Her serum osmolality was $428 \mathrm{mosm} / \mathrm{L}$, and urine osmolarity was $268 \mathrm{mosm} / \mathrm{L}$.

Vasopressin infusion was started for suspected coexistent diabetes insipidus. However, the urine output fell drastically with vasopressin, and so it was omitted. In addition to the standard ongoing fluid management of DKA, the free water correction was done using Madias formula by hourly enteral administration to lower her serum sodium gradually by 12 $\mathrm{mEq} / 24 \mathrm{~h}{ }^{\left[{ }^{[3]}\right.}$ The urine output $>4 \mathrm{ml} / \mathrm{kg} / \mathrm{h}$ was replaced hourly by an equal volume of 0.33 DNS intravenously. Serum sodium was monitored two hourly, and fluids titrated to permit a steady fall in serum sodium of $0.5 \mathrm{mEq} / \mathrm{h}$.

She had two episodes of generalized tonic-clonic convulsions which were controlled with phenytoin. In view of the possibility of a coexisting viral encephalitis, IV acyclovir was added empirically. On day 3 of admission, the child developed thrombus in the left radial artery. The arterial line was removed, and the patient was started on low-molecular-weight (LMW) heparin in the therapeutic dosage. Later, she developed gangrenous change of the tip of the left index finger. She also developed extensive superficial and deep venous thrombosis with Doppler suggestive of thrombosis in the right external iliac vein, common femoral, proximal superficial, and deep femoral vein. Her prothrombin time was $12.6 \mathrm{~s}$ with international normalized ratio 1.26, partial thromboplastin time $36 \mathrm{~s}$, serum fibrinogen of $211 \mathrm{mg} / \mathrm{dL}(\mathrm{N}-150-400 \mathrm{mg} / \mathrm{dL}$ ), and D-dimer of 8749 microgram $/ \mathrm{L}(\mathrm{N}-<500 \mu \mathrm{g} / \mathrm{L})$. The femoral catheter was removed, and right internal jugular venous catheter was placed. The inotropes and vasopressors were gradually tapered and omitted. The two-dimensional echocardiogram and magnetic resonance imaging brain were normal. Her acidosis gradually resolved. Serum sodium returned to normal over 7 days falling at a steady rate of $10-12 \mathrm{mEq} /$ day [Figure 1].

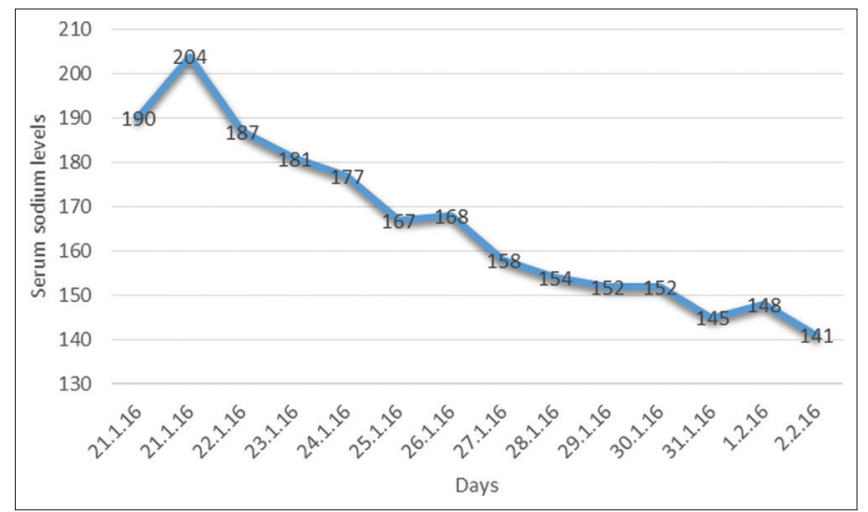

Figure 1: Serum sodium levels over the first 2 weeks
On day 4 of admission, she developed large blisters and denudation of skin over the buttocks, groin, right forearm, and right lower limb [Figure 2].

On day 6 , she developed fever with a progressive fall in platelet count to $8000 / \mu \mathrm{L}$. Blood and urine culture grew Candida albicans and tropicalis and was treated with fluconazole as per sensitivity report. Acyclovir was omitted. The blisters gradually resolved. The child was extubated on day 10 and put on high-flow humidified nasal cannula from which she was gradually weaned off.

Steady sodium correction with target decline of $10-12 \mathrm{mEq} /$ day was achieved by titrating the tonicity of the maintenance fluid, free water deficit correction, and replacing the excessive urinary losses.

Insulin infusion and glucose content of the IV fluid was titrated with a target blood sugar of 150-200 mg/dL. LMW heparin was continued till the resolution of arterial and venous thrombosis. She was positive for tissue transglutaminase, but endomyesial, antiglutamic acid decarboxylase, and islet-cell antibody titers were negative. She was advised a gluten-free diet. At 1 month after admission, she was neurologically normal, her diabetes under control with complete healing of her skin and total resolution of the arterial and venous thrombosis.

\section{Discussion}

Anecdotal reports of hypernatremia in adolescent children with DKA have been attributed to large intake of carbonated drinks or the use of herbal products. ${ }^{[4-6]}$ Our patient had no history of such intake.

None of these patients was as young as our patient or had such extreme hypernatremia. Due to the early onset of DKA, extreme hypernatremia, and polyuria, Wolfram syndrome with diabetes insipidus, diabetes mellitus, and optic atrophy was considered as a possibility. However, the absence of optic atrophy as well as the total disappearance of polyuria after recovery made the diagnosis unlikely.

The extreme hypernatremia was primarily due to large electrolyte-free water losses associated with osmotic diuresis. This may have got aggravated during therapy because of the

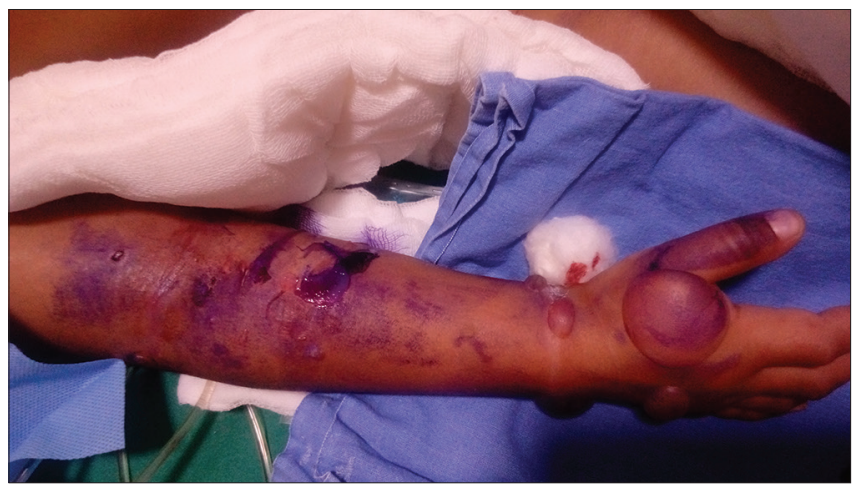

Figure 2: Blisters on forearm 
large amount of sodium she received in her fluid management according to the standard DKA protocol and the failure to replace the large urinary free water losses.

Deep vein thrombosis associated with femoral vein catheterization has been reported in diabetics, and cannulation of central veins should preferably be avoided. In our patient, the unstable hemodynamic state necessitated both arterial and femoral vein cannulation. The extremely hyperosmolar state resulting from hyperglycemia with added hypernatremia was probably responsible for the arterial as well as the extensive deep and superficial vein thrombosis in our child. ${ }^{[7,8]}$ Fatal transverse sinus thrombosis has been described in a 2-week-old baby with a serum sodium $>200 \mathrm{mEq} / \mathrm{L} .{ }^{[9]}$ The current recommendations for DKA do not support the use of prophylactic anticoagulation.

Blistering has been reported with acyclovir use, and in our patient, new blisters stopped appearing after omission of acyclovir. ${ }^{[10]}$

Extreme hypernatremia is a catastrophic condition that is known to be associated with death or severe neurological sequelae in survivors. The intact neurological survival was probably related to the very gradual reduction in serum sodium to normal levels over almost 10 days using a pathophysiological-based fluid management.

\section{Financial support and sponsorship}

Nil.

\section{Conflicts of interest}

There are no conflicts of interest.

\section{REFERENCES}

1. Wolfsdorf J, Glaser N, Sperling MA; American Diabetes Association. Diabetic ketoacidosis in infants, children, and adolescents: A consensus statement from the American Diabetes Association. Diabetes Care 2006;29:1150-9

2. Frier BM, Steer CR, Baird JD, Bloomfield S. Misleading plasma electrolytes in diabetic children with severe hyperlipidaemia. Arch Dis Child 1980;55:771-5.

3. Barsoum NR, Levine BS. Current prescriptions for the correction of hyponatraemia and hypernatraemia: Are they too simple? Nephrol Dial Transplant 2002;17:1176-80.

4. McDonnell CM, Pedreira CC, Vadamalayan B, Cameron FJ, Werther GA. Diabetic ketoacidosis, hyperosmolarity and hypernatremia: Are high-carbohydrate drinks worsening initial presentation? Pediatr Diabetes 2005;6:90-4.

5. Vanelli M, Chiari G, Ghizzoni L, Capuano C, Bonetti L, Costi G, et al. Ketoacidosis and hyperosmolarity as first symptoms of type 1 diabetes mellitus following ingestion of high-carbohydrate-containing fluids. J Pediatr Endocrinol Metab 1999;12:691-4.

6. Bhowmick SK, Hundley OT, Rettig KR. Severe hypernatremia and hyperosmolality exacerbated by an herbal preparation in a patient with diabetic ketoacidosis. Clin Pediatr (Phila) 2007;46:831-4.

7. Worly JM, Fortenberry JD, Hansen I, Chambliss CR, Stockwell J. Deep venous thrombosis in children with diabetic ketoacidosis and femoral central venous catheters. Pediatrics 2004;113(1 Pt 1):e57-60.

8. Gutierrez JA, Bagatell R, Samson MP, Theodorou AA, Berg RA. Femoral central venous catheter-associated deep venous thrombosis in children with diabetic ketoacidosis. Crit Care Med 2003;31:80-3.

9. van Amerongen RH, Moretta AC, Gaeta TJ. Severe hypernatremic dehydration and death in a breast-fed infant. Pediatr Emerg Care 2001; $17: 175-80$

10. Gurkan A, Erkek N, Senel S. Localized bullous eruptions away from infusion site due to intravenous acyclovir administration in a child. Indian J Pharmacol 2012;44:126-8. 